\title{
Research Article \\ Burden of Sickle Cell Disease in Ghana: The Korle-Bu Experience
}

\author{
Eugenia V. Asare, ${ }^{1,2}$ Ivor Wilson, ${ }^{1}$ Amma A. Benneh-Akwasi Kuma $\left(\mathbb{D},{ }^{3}\right.$ \\ Yvonne Dei-Adomakoh $\circledast^{1,3}$ Fredericka Sey, ${ }^{1}$ and Edeghonghon Olayemi $\circledast^{1,3}$ \\ ${ }^{1}$ Ghana Institute of Clinical Genetics, Korle-Bu, Accra, Ghana \\ ${ }^{2}$ Department of Haematology, Korle-Bu Teaching Hospital, Accra, Ghana \\ ${ }^{3}$ Department of Haematology, College of Health Sciences, University of Ghana, Accra, Ghana \\ Correspondence should be addressed to Edeghonghon Olayemi; eolayemi@ug.edu.gh
}

Received 20 September 2018; Accepted 11 November 2018; Published 2 December 2018

Academic Editor: Estella M. Matutes

Copyright (c) 2018 Eugenia V. Asare et al. This is an open access article distributed under the Creative Commons Attribution License, which permits unrestricted use, distribution, and reproduction in any medium, provided the original work is properly cited.

\begin{abstract}
In Africa, sickle cell disease (SCD) is a major public health problem with over 200,000 babies born per year. In Ghana, approximately $15,000(2 \%)$ of Ghanaian newborns are diagnosed with SCD annually. A retrospective review of medical records of all SCD patients aged 13 years and above, who presented to the sickle cell clinic at Ghana Institute of Clinical Genetics (GICG), Korle-Bu, from 1st January 2013 to 31st December 2014, was carried out, using a data abstraction instrument to document their phenotypes, demographics, attendance/clinic visits, pattern of attendance, and common complications seen. During the period under review 5,451 patients were seen at the GICG, with 20,788 clinic visits. The phenotypes were HbSS (55.7\%) and HbSC (39.6\%) with other sickle cell phenotypes (4.7\%). Out of the 20,788 clinic visits, outpatient visits were 15,802 (76\%), and urgent care visits were 4,986 (24\%), out of which 128 (2.6\%) patients were admitted to the Teaching Hospital for further management of their acute complications. There were 904 patient referrals (out of 5,451 patients) for specialist care; the 3 specialties that had the most referrals were Obstetrics and Gynaecology (168 patients), Orthopaedics (150 patients), and Ophthalmology (143 patients). In 2014, complications seen at KBTH included 53 patients with avascular necrosis (AVN) and 61 patients with chronic leg ulcers. Our centre has a large number of patients living with sickle cell disease. From our experience, early recognition and referral of sickle cell related complications can reduce morbidity and mortality associated with this disease. A multidisciplinary approach to care of SCD patients is therefore important.
\end{abstract}

\section{Introduction}

Genetic diseases are very common; and it has been estimated that more than 7 million babies are born each year with a congenital genetic abnormality [1].

Sickle cell disease (SCD) is the most common haemoglobinopathy [1]; it is characterized by inheritance of 2 abnormal haemoglobins of which one is haemoglobin $\mathrm{S}(\mathrm{HbS})$. Haemoglobin $\mathrm{S}(\mathrm{HbS}$ ) is a structural variant of normal adult haemoglobin $(\mathrm{HbA})$, inherited as an autosomal recessive Mendelian trait. The most common clinical phenotype is the homozygous form (HbSS or sickle cell anaemia). Compound heterozygous SCD include HbSC, HbSD, HbSO-Arab, and $\mathrm{HbS} / \mathrm{beta}$-thalassemia. Heterozygotes are generally less symptomatic compared to those who are homozygous [2].
Sickle cell disease is a major public health problem with over 200,000 babies born per year with SCD in Africa $[3,4]$. Approximately $80 \%$ of all children born with SCD are in subSaharan Africa $[1,5]$. In Ghana, $2 \%$ (about 15,000) of newborns have SCD, with $55 \%$ of them having the homozygous form [6].

Clinical features of SCD include acute pain episodes (which are the hallmark of the disease), anaemia, recurrent infections, and chronic end-organ damage $[7,8]$. Newborn screening with early diagnosis and comprehensive care [916] has been shown to improve survival since the disease has a high mortality rate in the first few years of life. In 2010, Quinn et al. reported an increased life expectancy in the American SCD population, with over $90 \%$ of babies born with SCD currently reaching adulthood [17]. 
Despite the high prevalence of SCD in Ghana, the extent of the burden of the disease in adults is yet to be quantified and the life expectancy of the Ghanaian SCD patient is not known, though it is generally agreed that more children with the disease now survive into adulthood. Many of the newer modalities of management such as hydroxyurea are not widely used.

The Ghana Institute of Clinical Genetics (GICG) was established in Korle-Bu, Accra, Ghana, in 1974 and currently provides comprehensive outpatient care to both adolescents and adults with SCD, along with community education and research. The premier adult sickle cell clinic in Ghana is located in the institute with the largest number of registered adolescent and adult SCD patients in Ghana. The clinic receives patients (adolescents and adults) from all over Ghana but mainly from the southern part of the country.

This study was designed to outline the burden of sickle cell disease at the GICG and identify the common complications.

\section{Materials and Methods}

2.1. Study Design. A retrospective two-year chart review of all patient folders and records from January 1st, 2013, to December 31st, 2014, was carried out [2]. Institutional approval was obtained from GICG.

2.2. Study Sites. The GICG located on the campus of Korle$\mathrm{Bu}$ Teaching Hospital renders outpatient services through an outpatient department and an urgent care unit. Referrals are received from other healthcare facilities all over Ghana. It has over 25,000 registered SCD patients. Every year, the clinic records between 10,000 and 15,000 clinic visits with an average daily attendance of almost 50 patients. Patients who need further specialist care are referred to the Teaching Hospital.

2.3. Study Population. The study population was made up of all SCD patients aged 13 years and above who presented to GICG and KBTH within the study period.

2.4. Data Collection. The demographic characteristics, clinical information, and pattern of attendance were obtained from the case files of all eligible patients. A data extraction form was used to document demographic characteristics and clinical information such as age, sex, sickle cell phenotypes, and sickle cell related complications (the data on SCD complications was extracted from the following departments at the Korle-Bu Teaching Hospital: Obstetrics and Gynaecology, Orthopaedics, Ophthalmology, and Urology). The World Health Organization (WHO) age group classification was used as follows: adolescents from 10 to 19 years, adults from 20 to 59 years (young adults from 20 to 39 years; middle age from 40 to 59 years), and elderly from 60 years and above [18]. The age group from 15 to 44 years is considered the reproductive age [18]. For the purposes of this study, our adolescent age group started from 13 to 19 years, because at our centre patients below 13 years are seen in the paediatric department.
2.5. Data Storage and Management. The data collected from the medical records was limited to only information that was necessary to the study. No personal identifiable data was collected. Only the authors had access to the data.

2.6. Data Analysis. Data were captured using Microsoft Access 2010 version, analysed using Excel (windows version 10), reported with simple descriptive statistics such as proportions, ratios, percentages, tables, and histograms.

\section{Results}

3.1. Phenotypic Patient Burden at GICG. Over the period of review, 5,451 adolescent and adult SCD patients were seen at the study site, with 20,788 clinic visits. The phenotypes were $\mathrm{HbSS}(55.7 \%)$, HbSC (39.6\%), and other sickle cell phenotypes $(4.7 \%)$. The male-to-female ratio was $1: 1.6$. The ages of patients seen at the clinic during the review ranged from 13 to 87 years with a higher proportion of young adults and middle-aged patients (Figure 1). A third (1,400) of the patients were in the reproductive age group. From age 13 to 44 years, there were more HbSS patients as compared to HbSC (ratio of 2:1). However, this was reversed after the age of 44 years.

3.2. Clinic Visits. Over the two-year study period, there were 20,788 clinic (GICG) visits made by the SCD patients. Approximately $27.5 \%$ of the patients made one clinic visit, $52.7 \%$ made 2 to 5 clinic visits, and $19.8 \%$ made $>12$ clinic visits per year (Figure 2).

Patients with HbSS phenotype were responsible for $61 \%$ of the clinic visits compared with $34 \%$ for HbSC and 5\% for other phenotypes.

Clinic attendance was highest in January (approximately 1000) and lowest in December (approximately 700), with another increase seen from early May to late July (Table 1).

3.3. Proportion of SCD Patients Who Had Further Specialist Care at KBTH. During the study period, out of 5,451 patients seen, $904(16.6 \%)$ were referred for specialist care at the Teaching Hospital (Table 2). The three specialties that had the most referrals were the Obstetrics and Gynaecology clinic (168 patients), the Orthopaedic clinic (150 patients), and the Ophthalmology clinic (143 patients).

3.4. Common Complications Confirmed in Patients Referred for Specialist Care. Records from the Orthopaedics department, KBTH, in 2014 showed that $53(68.8 \%)$ out of 77 SCD patients seen were diagnosed with radiological evidence of avascular necrosis (AVN). Most patients were diagnosed between the ages of 20-24 years. Forty-nine (92.5\%) of these had AVN of the femoral head and 4 (7.5\%) had AVN of the humeral head. Only 4 of them had bilateral AVN of the femoral head.

At the Ophthalmology department, 16 (18.6\%) out of the 86 patients seen in 2014 were diagnosed with sickle cell retinopathy. Twenty-eight (51.9\%) of 54 patients seen by the urologists in 2014 had priapism. 
TABLE 1: Pattern of attendance at GICG (2013-2014).

\begin{tabular}{|c|c|c|c|c|c|c|c|c|c|c|c|c|}
\hline & 2013 & & & & & & 2014 & & & & & \\
\hline Month & HbSS & HbSC & Other & Total & New patients & D.A.A & HbSS & HbSC & Other & Total & New patients & DAA \\
\hline January & 620 & 350 & 56 & 1026 & 25 & 46.64 & 656 & 333 & 55 & 1044 & 16 & 47.45 \\
\hline February & 540 & 294 & 48 & 888 & 24 & 44.40 & 492 & 299 & 33 & 825 & 12 & 41.25 \\
\hline March & 514 & 240 & 38 & 790 & 36 & 41.58 & 517 & 296 & 29 & 854 & 19 & 42.70 \\
\hline April & 330 & 173 & 27 & 530 & 7 & 29.44 & 468 & 275 & 39 & 783 & 16 & 39.15 \\
\hline May & 551 & 275 & 42 & 868 & 20 & 41.33 & 532 & 324 & 41 & 898 & 14 & 44.90 \\
\hline June & 537 & 311 & 69 & 919 & 16 & 45.95 & 488 & 312 & 46 & 849 & 16 & 40.43 \\
\hline July & 621 & 364 & 29 & 1017 & 27 & 46.23 & 523 & 276 & 41 & 842 & 13 & 40.10 \\
\hline August & 600 & 343 & 49 & 993 & 28 & 47.29 & 578 & 316 & 46 & 940 & 16 & 44.77 \\
\hline September & 576 & 307 & 25 & 908 & 13 & 45.40 & 531 & 343 & 43 & 919 & 15 & 43.76 \\
\hline October & 577 & 342 & 39 & 958 & 21 & 43.55 & 443 & 262 & 32 & 737 & 15 & 33.50 \\
\hline November & 550 & 313 & 51 & 913 & 24 & 43.48 & 492 & 272 & 36 & 804 & 14 & 40.20 \\
\hline December & 478 & 269 & 40 & 787 & 10 & 41.42 & 427 & 241 & 29 & 696 & 16 & 34.80 \\
\hline Total & 6494 & 3581 & 513 & 10597 & 251 & 43.06 & 6147 & 3549 & 470 & 10191 & 182 & 41.08 \\
\hline
\end{tabular}

DAA: Daily Average Attendance.

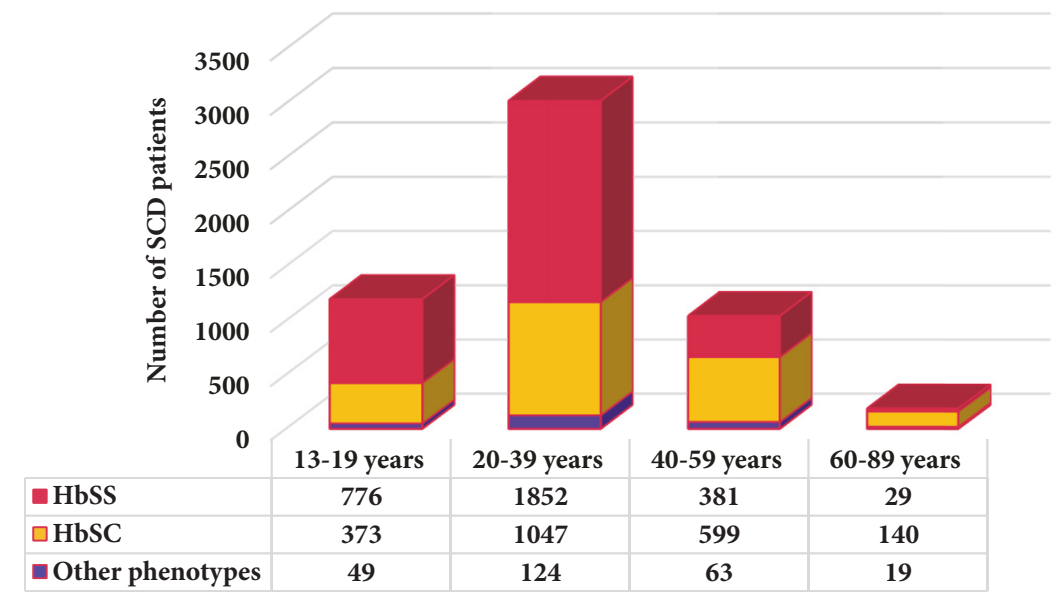

FIGURE 1: Age group and phenotypes of SCD patients.

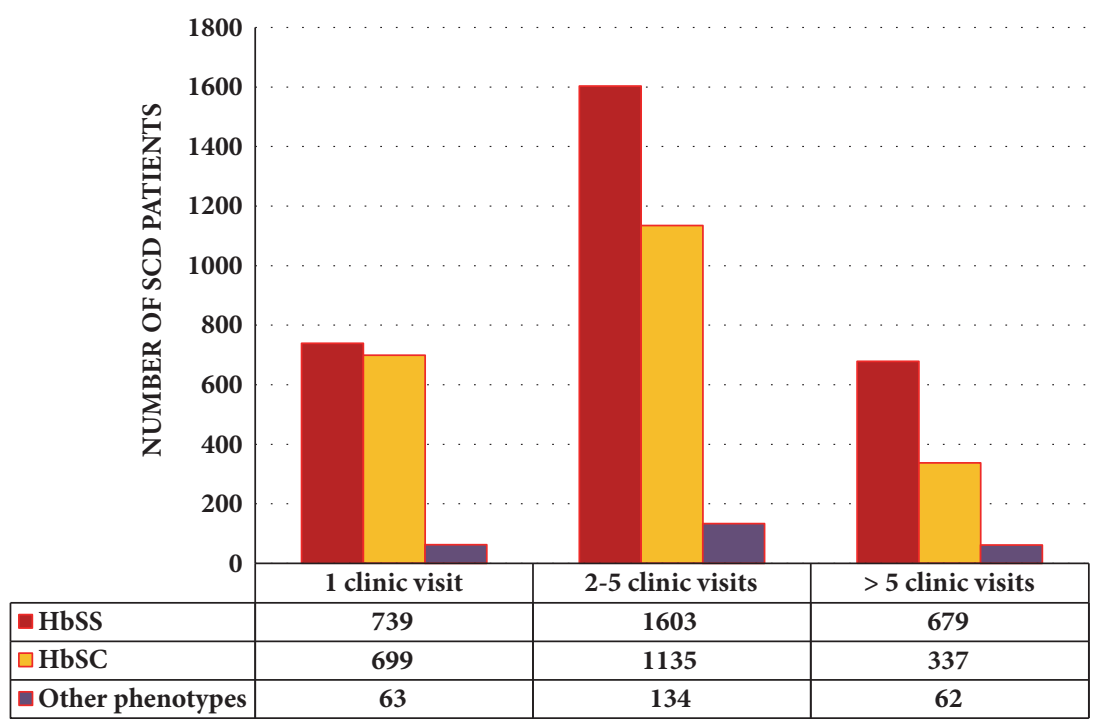

FIGURE 2: Clinic visits by phenotypes. 
TABLE 2: SCD patients referred for specialist care.

\begin{tabular}{lccc}
\hline Specialty & $\mathbf{2 0 1 3}$ & $\mathbf{2 0 1 4}$ & Total \\
\hline Obstetrics & 77 & 91 & 168 \\
Orthopaedics & 75 & 75 & 150 \\
Ophthalmology & 70 & 73 & 143 \\
Plastics/general surgery & 20 & 53 & 73 \\
Urology & 27 & 21 & 48 \\
Nephrology & 9 & 12 & 21 \\
Others & 153 & 148 & 301 \\
Total & $\mathbf{4 3 1}$ & $\mathbf{4 7 3}$ & $\mathbf{9 0 4}$ \\
\hline
\end{tabular}

3.5. Proportion of SCD Patients Seen at GICG with Chronic Leg Ulcers. At the end of 2014, 61 SCD patients were seen at the GICG with chronic leg ulcers who were referred to either the general surgical or plastic surgery units. Chronic leg ulcers were more common in the male sex and phenotype SS and were mostly unilateral.

\section{Discussion}

Sickle cell disease is a major public health problem in Africa, where over 200,000 babies are born with the disease per year $[3,4]$; and about $80 \%$ of all children born with SCD are in subSaharan Africa $[1,5]$. There were more patients with HbSS compared to HbSC in our study (55.7\% versus $39.6 \%$ ) with a higher female-to-male ratio (1.6:1). This agrees with an earlier study by Ohene-Frempong et al. (2008) from Ghana, which showed that $55 \%$ of children born with SCD in Ghana had HbSS [6]. From ages of 13 to 44 years, the ratio of HbSS to HbSC was 2:1; this was reversed after 44 years possibly as a result of the higher mortality seen in HbSS patients who have been documented to have a more severe form of the disease [19].

The slightly higher female-to-male ratio in our study may be due to the better health seeking habits of females as compared to males [20] and the fact that in most populations women live longer than men [21]. It is therefore not surprising to see that the women in our cohort had better health maintenance, judging by their attendance. In Ghana, according to WHO data published in 2015, the life expectancy (in years) at birth for the Ghanaian male is 61.0 and the Ghanaian female is 63.9 [21]. This may also contribute to the male-to-female ratio of 1:1.6 seen in this cohort.

Expectedly, HbSS patients accounted for more clinic visits (61\%) than other SCD phenotypes, since they are known to have a more severe form of SCD [19].

The effect of the Ghanaian climate was also seen in the pattern of clinic attendance by our patients. Ghana has a tropical climate; temperature in the country varies with season and elevation. In the Southern part of the country where Accra is located, two rainy seasons occur, from April to July and from September to November. The Harmattan, a dry desert wind, blows from the northeast from December to March. The Harmattan lowers humidity, creating hot days and cool nights in the north. In the south, the effects of the Harmattan are felt in January. In most parts of Ghana, the highest temperatures occur in March and the lowest in August [22].

Clinic attendance was lowest in December, probably because of the festive season, and highest after the festive season in January, which is often the peak of Harmattan season with cold, dry conditions, which predisposes SCD patients to developing crises. There was another peak from May to July as a result of the frequent rainfall, cold, and very humid weather conditions; these along with the increase in incidence of malaria [23] may also predispose our patients to ill-health and crises.

Unpublished data from KBTH shows that approximately 200 pregnant women with SCD are seen at the antenatal clinic each year. Despite the well-documented high rates of maternal and foetal morbidity and mortality in pregnant women with SCD [24], there is still a paucity of preconception care or family planning in this population $[25,26]$. Given these pregnancy-associated problems for women with SCD, advice about both pregnancy planning and effective contraception is of paramount importance [27].

Our data showed that over 900 patients were referred for further specialist's care and that three specialties (Obstetrics and Gynaecology, Orthopaedics, and Ophthalmology) had over $50 \%$ of the referrals. With improved care, more children with SCD now survive into adulthood and are now prone to chronic complications which are more common in adults such as avascular necrosis and retinopathies.

\section{Conclusions}

Our study confirms that Ghana has a large burden of SCD; a pilot newborn screening program in one of the ten regions of Ghana has shown prevalence of $1.8 \%$, which translates to about 15,000 babies with SCD being born in Ghana every year [6]. It is likely that, with appropriate use of basic medical facilities, more children with SCD now survive into adulthood with the oldest patient in our cohort now in her late 80s. It is almost certain that if Ghana and other African countries are to make an appreciable impact on the care of people living with SCD, more attention has to be paid to providing multidisciplinary care including adequate care at the primary level along with the development and implementation of a national sickle cell disease policy which will include but will not be limited to universal new born screening [28].

\section{Data Availability}

The data used to support the findings of this study are available to researchers who meet the criteria for access to confidential data from the corresponding author upon request. This will be done after approval of the request by the management committee, Ghana Institute of Clinical Genetics.

\section{Conflicts of Interest}

The authors declare that there are no conflicts of interest regarding the publication of this paper. 


\section{Authors' Contributions}

Eugenia V. Asare and Edeghonghon Olayemi conceived the idea; Ivor Wilson and Eugenia V. Asare performed the data search; Eugenia V. Asare, Ivor Wilson, Amma A. BennehAkwasi Kuma, Yvonne Dei-Adomakoh, Fredericka Sey, and Edeghonghon Olayemi analysed the data. All authors participated in writing the article and reviewed and approved the final version before submission.

\section{Acknowledgments}

The authors acknowledge the help of the following: (i) Staff, Records Department, Ghana Institute of Clinical Genetics, Korle-Bu, Accra, Ghana; (ii) Dr. Amgbo Asare, Department of Trauma and Orthopaedics, Korle-Bu Teaching Hospital, Korle-Bu, Accra, Ghana; (iii) Dr. Samuel Antwi Oppong, Department of Obstetrics and Gynaecology, School of Medicine and Dentistry, University of Ghana, Accra, Ghana; and (iv) Ms. Mary Ampomah, Ghana Institute of Clinical Genetics, Korle-Bu, Accra, Ghana.

\section{References}

[1] B. Modell and M. Darlison, "Global epidemiology of haemoglobin disorders and derived service indicators," Bulletin of the World Health Organization, vol. 86, no. 6, pp. 480-487, 2008.

[2] D. C. Rees, T. N. Williams, and M. T. Gladwin, "Sickle-cell disease," The Lancet, vol. 376, no. 9757, pp. 2018-2031, 2010.

[3] Press Conference On Raising Awareness Of Sickle-Cell Anaemia-Meetings Coverage and Press Releases. http://www .un.org/press/en/2009/090619_Anaemia.doc.htm.

[4] D. Diallo and G. Tchernia, "Sickle cell disease in Africa," Current Opinion in Hematology, vol. 9, no. 2, pp. 111-116, 2002.

[5] F. B. Piel, A. P. Patil, R. E. Howes et al., "Global epidemiology of Sickle haemoglobin in neonates: a contemporary geostatistical model-based map and population estimates," The Lancet, vol. 381, no. 9861, pp. 142-151, 2013.

[6] K. Ohene-Frempong, J. Oduro, H. Tetteh, and F. Nkrumah, "Screening newborns for sickle cell disease in Ghana," Pediatrics, vol. 121, pp. S120-S121, 2008.

[7] T. N. Williams, S. Uyoga, A. Macharia et al., "Bacteraemia in Kenyan children with sickle-cell anaemia: a retrospective cohort and case-control study," The Lancet, vol. 374, no. 9698, pp. 1364-1370, 2009.

[8] J. A. G. Scott, J. A. Berkley, I. Mwangi et al., "Relation between falciparum malaria and bacteraemia in Kenyan children: A population-based, case-control study and a longitudinal study," The Lancet, vol. 378, no. 9799, pp. 1316-1323, 2011.

[9] C. J. Wang, P. L. Kavanagh, A. A. Little, J. B. Holliman, and P. G. Sprinz, "Quality-of-care indicators for children with sickle cell disease," Pediatrics, vol. 128, no. 3, pp. 484-493, 2011.

[10] M. P. Cober and S. J. Phelps, "Penicillin prophylaxis in children with sickle cell disease," The Journal of Pediatric Pharmacology and Therapeutics, vol. 15, no. 3, pp. 152-159, 2010.

[11] R. Hardie, L. King, R. Fraser, and M. Reid, "Prevalence of pneumococcal polysaccharide vaccine administration and incidence of invasive pneumococcal disease in children in Jamaica aged over 4 years with sickle cell disease diagnosed by newborn screening," Annals of Tropical Paediatrics, vol. 29, no. 3, pp. 197202, 2009.

[12] A. M. Ellison, K. V. Ota, K. L. McGowan, and K. Smith-Whitley, "Pneumococcal bacteremia in a vaccinated pediatric sickle cell disease population," The Pediatric Infectious Disease Journal, vol. 31, no. 5, pp. 534-536, 2012.

[13] M. T. Lee, S. Piomelli, S. Granger et al., "Stroke prevention Trial in Sickle Cell Anaemia (STOP): extended Follow up and final results," Blood, vol. 108, no. 3, pp. 847-852, 2006.

[14] J. Malouf A.J., J. E. Hamrick-Turner, M. C. Doherty, G. S. Dhillon, R. V. Iyer, and M. G. Smith, "Implementation of the STOP protocol for stroke prevention in sickle cell anemia by using duplex power doppler imaging," Radiology, vol. 219, no. 2, pp. 359-365, 2001.

[15] S. Charache, "Hydroxyurea as treatment for sickle cell anemia," Hematology/Oncology Clinics of North America, vol. 5, no. 3, pp. 571-583, 1991.

[16] M. M. Heeney and R. E. Ware, "Hydroxyurea for Children with Sickle Cell Disease," Hematology/Oncology Clinics of North America, vol. 24, no. 1, pp. 199-214, 2010.

[17] C. T. Quinn, Z. R. Rogers, T. L. McCavit, and G. R. Buchanan, "Improved survival of children and adolescents with sickle cell disease," Blood, vol. 115, no. 17, pp. 3447-3452, 2010.

[18] Women's health [Internet]. World Health Organization. http:// www.who.int/news-room/fact-sheets/detail/women-s-health.

[19] J. Kanter and R. Kruse-Jarres, "Management of sickle cell disease from childhood through adulthood," Blood Reviews, vol. 27, no. 6, pp. 279-287, 2013.

[20] A. E. Thompson, Y. Anisimowicz, B. Miedema, W. Hogg, W. P. Wodchis, and K. Aubrey-Bassler, "The influence of gender and other patient characteristics on health care-seeking behaviour: A QUALICOPC study," BMC Family Practice, vol. 17, no. 1, 2016.

[21] Global Health Observatory data repository-By category-Life expectancy and healthy life expectancy - Data by WHO region. WHO. http://apps.who.int/gho/data/view.main. SDG2016LEXREGv?lang=en.

[22] Ghana: Geography, Location, weather etc. https://www.ghanaweb .com/GhanaHomePage/geography/climate.php.

[23] T. A. Abeku, "Response to malaria epidemics in Africa," Emerging Infectious Diseases, vol. 13, no. 5, pp. 681-686, 2007.

[24] T. K. Boafor, E. Olayemi, N. Galadanci et al., "Pregnancy outcomes in women with sickle-cell disease in low and high income countries: A systematic review and meta-analysis," BJOG: An International Journal of Obstetrics \& Gynaecology, vol. 123, no. 5, pp. 691-698, 2016.

[25] B. M. Ramesh, S. C. Gulati, and R. D. Retherford, "Contraceptive use in India, 1992-93," National Family Health Survey Subject Reports, International Institute for Population Sciences, October 1996.

[26] K. B. Parmar, S. L. Kantharia, N. R. Godara, H. M. Shah, and M. M. Patni, "A cross-sectional study to understand socio demographic profile of couples who adopted permanent sterilization in urban slums of Surat city," National Journal of Community Medicine, vol. 4, no. 3, pp. 443-448, 2013.

[27] A. A. Eissa, S. M. Tuck, K. Rantell, and D. Stott, "Trends in family planning and counselling for women with sickle cell disease in the UK over two decades," Journal of Family Planning and Reproductive Health Care, vol. 41, no. 2, pp. 96-101, 2015.

[28] N. Galadanci, B. J. Wudil, T. M. Balogun et al., "Current sickle cell disease management practices in Nigeria," International Health, vol. 6, no. 1, pp. 23-28, 2014. 


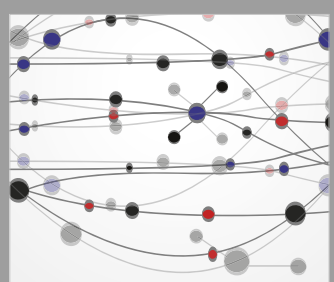

The Scientific World Journal
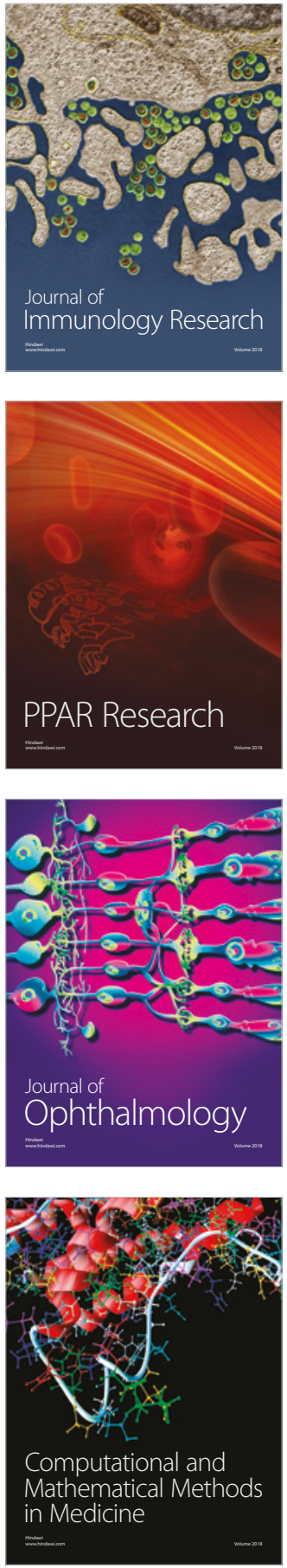

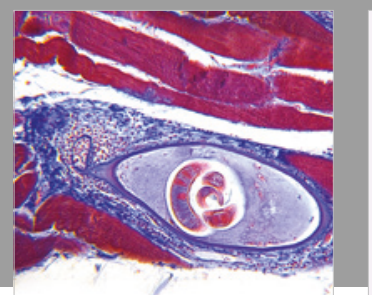

Gastroenterology Research and Practice

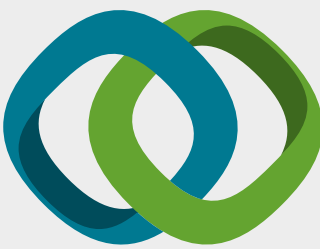

\section{Hindawi}

Submit your manuscripts at

www.hindawi.com
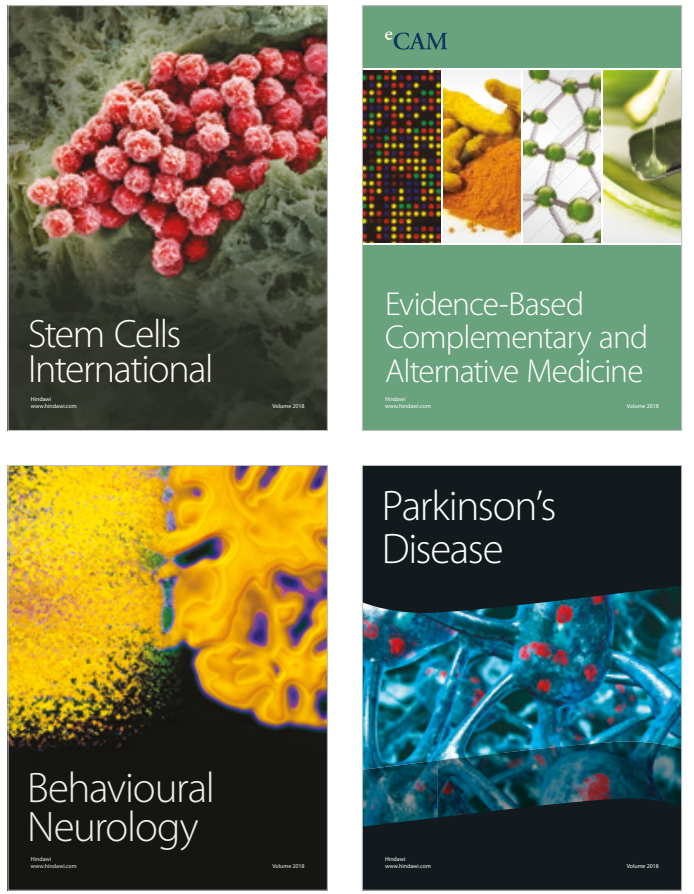

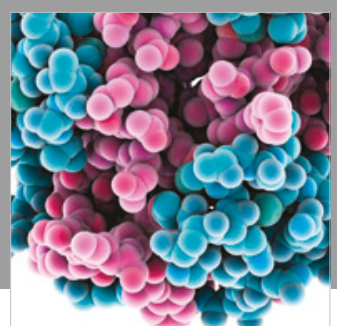

ournal of

Diabetes Research

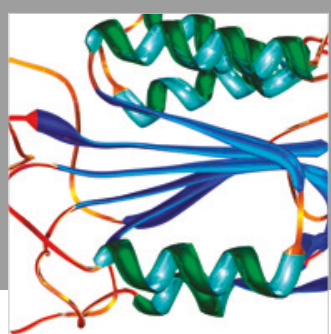

Disease Markers
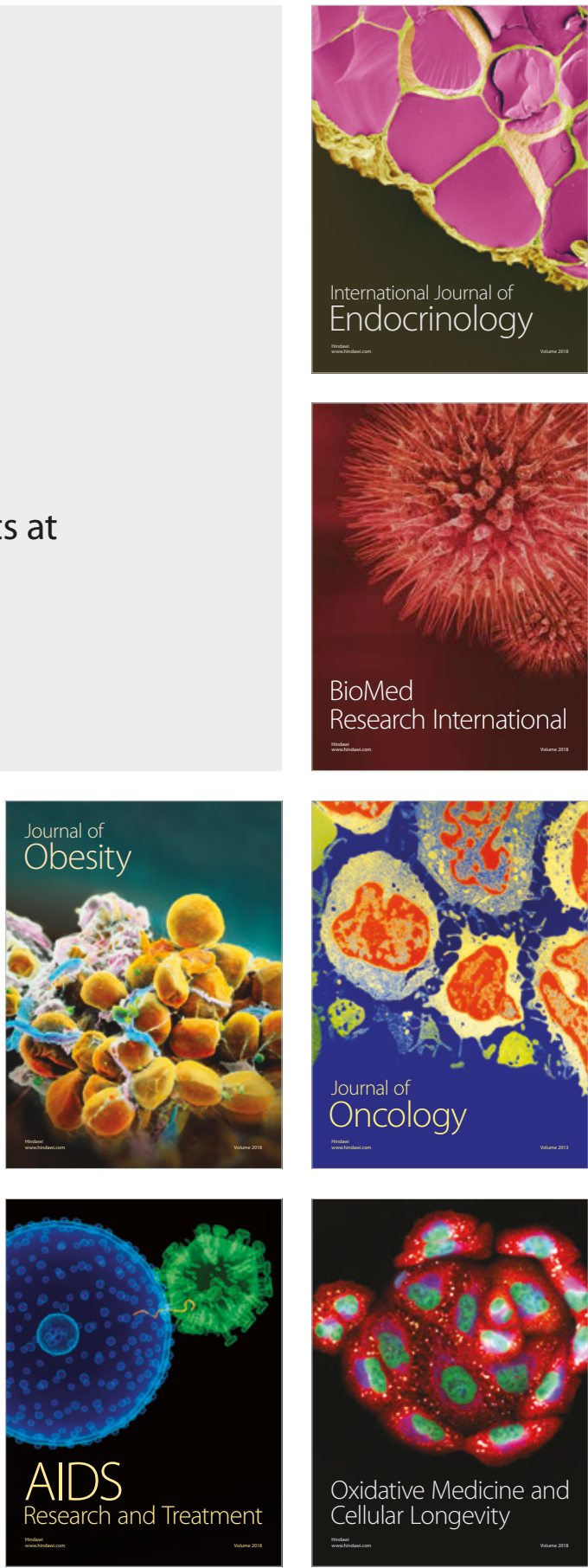